\title{
Significant Predictors of Underutilization of Inpatient Benefits among PhilHealth Members in Selected Barangays in Manila
}

\author{
Emerito Jose A. Faraon, ${ }^{1}$ Josue Antonio G. Estrada, ${ }^{2}$ Ena Lauren F. Farillas, ${ }^{2}$ \\ Francis Regis D. Mabera, ${ }^{2}$ Arwin Marie P. Paras, ${ }^{2}$ Maria Katrina R. Pastrana ${ }^{2}$ and Albert Mitchell L. Yap ${ }^{2}$ \\ ${ }^{1}$ Department of Health Policy and Administration, College of Public Health, University of the Philippines Manila \\ ${ }^{2}$ College of Public Health, University of the Philippines Manila
}

\begin{abstract}
Background. Underutilization of PhilHealth benefits undermines the effective distribution of public resources. To formulate effective strategies, the factors affecting the utilization of members must be studied.
\end{abstract}

Objectives. To (1) assess the rate of underutilization of inpatient benefits and (2) determine the association of chosen factors with PhilHealth underutilization of selected member groups in three barangays in Manila.

Methods. The study was done in selected Barangays in Manila. Using the Expanded Program on Immunization (EPI) method of sampling, a sample size of 147 households were obtained and interviewed for the study. An interview guide was used to gather the data needed for analysis. Chi-square test was then used to determine existing associations between underutilization and the chosen factors.

Results and Conclusion. The chi-square test of association revealed that gender ( $p$-value $=0.034)$, income ( $p$-value $=0.026$ ), and type of membership ( $p$-value $=0.027$ ) are significantly associated with underutilization. Females and paying members were found to be more frequent users. Gap between the utilization and underutilization rates was found to be greatest in the lowest income groups. 'Lack of knowledge on filing claims' ( $p$ value $<0.001)$ and on benefits ( $p$-value $<0.001)$ were also identified as significant predictors of underutilization. Results showing a significant proportion of households experiencing insurance underutilization highlight the need for NHIC to create new and/or improved mechanisms that will enable it to extend its reach to the people.

Key Words: Social Health Insurance, inpatient benefits, hospitalization

Corresponding author: Emerito Jose A. Faraon, MD, MBA

Department of Health Policy and Administration

College of Public Health

University of the Philippines Manila

625 Pedro Gil St. Ermita, Manila 1000 Philippines

Telephone: +632 3104203

Email: eafaraon@up.edu.ph

\section{Introduction}

The National Health Insurance Corporation (NHIC) otherwise known as PhilHealth is the country's only social health insurance. Since 1995, it has been pursuing its ultimate goal - the provision of equitable access to healthcare for each and every Filipino. ${ }^{1}$ In more than two decades since its creation, it has produced many changes in the health sector but it is still far from achieving its goal of Universal Healthcare.

For 10 years (1995- 2005) households' Out-of-Pocket (OOP) shares, estimated at $40-50 \%$ of the Total Health Expenditure (THE), remain the highest in the country's THE. ${ }^{2}$ Tax-funded government shares, which have continually declined through the years, ranged only from 30 to $40 \%$ while that of the social health insurance went from 3.8 to $5.0 \% .^{2}$ Recent data from the Philippine National Health Accounts (PNHA) have shown that though both the National Government and PhilHealth's share in the THE has increased, the households' share still remains as the top contributor to the country's total expenditure in health. ${ }^{3}$ This only means that the larger burden on health care spending still falls on the Filipino households.

PhilHealth, as the country's only social health insurance, holds a special place in the health sector. Gaps in coverage among the populace have been at focus for several years and are considered a hindrance to Universal Health care (UHC). However, a less understood problem in underutilization is proving to be a bigger obstacle to PhilHealth's advance towards universal health care.

From 2002 to 2006, PhilHealth projected low utilization rates among members - the highest of which was in 2002 being merely $5.21 \%$ of the total utilization. ${ }^{2}$ The sponsored members - families in the bottom wealth quintile who are expected to have the highest utilization rate -, ironically, had the lowest utilization rates among all member groups.

Underutilization, defined as the inability to file insurance claims despite one's eligibility to do so, ${ }^{4}$ may be affected by several factors. In a study ${ }^{4}$ conducted in 2008, factors like transaction costs and level of education were presented as potential barriers to PhilHealth utilization. Factors related to the processing of claims and on knowledge on benefits may also affect the utilization of insurance among members. Several studies have shown that some socio-demographic, ${ }^{5-9}$ 
socioeconomic, ${ }^{4,5,10-14}$ and other factors such as the length of stay and type of membership ${ }^{4}$ among others are also related to health care and insurance utilization.

In this paper, we aim to determine factors which may affect underutilization, and we seek to assess the current rates of underutilization in an urban locality.

\section{Methods}

\section{Study Setting}

The study was conducted in three barangays located in Manila. These three barangays are situated in urban areas. They are also classified as residential and are among the 15 most populated barangays in the area - with one barangay being the most populated barangay in the said district. Located within the vicinity of two of the largest tertiary-level government-owned health institutions in the city - the Philippine General Hospital (PGH) and the Ospital ng Maynila (OM), these barangays are considered to have greater accessibility to low-cost high-end health care.

\section{Data Collection}

Included in the study were households with (1) at least one resident, PhilHealth member or dependent, who was hospitalized in the past 5 years; and (2) at least one resident who is a PhilHealth member and who has acquired his or her membership before the hospitalization of a dependent or of the member himself. Lifetime members were excluded from the study.

Underutilization was defined as the non-filing or nonapproval of filed claims. Households with multiple hospitalizations were classified 'underutilized' if, for at least one hospitalization, the member has failed to file a claim or if a filed claim was not approved.

The three communities, altogether, had a total household's population equal to 2,046. Latest information from the PhilHealth Geographic Information System (GIS) revealed $50.4 \%$ coverage for the National Capital Region (NCR), hence a total of 1,031 households in the barangay were assumed to have PhilHealth memberships. Data were collected from 147 households selected through the EPI method of sampling. An interview guide was used to collect information on socio-demographics, socio-economic status, and other factors deemed relevant to insurance utilization.

\section{Questionnaire}

The questionnaire which was administered with assistance among the chosen respondents was patterned after the questionnaire used by the National Statistics Office (NSO) in its National Demographic and Health Survey in 2008 (NDHS 2008). ${ }^{15}$ The questionnaire gives comprehensive information on aspects of health financing utilization among households.

\section{Data Analysis}

Gathered data were encoded using Epi $\operatorname{Info}^{\mathrm{TM}} 6$. Descriptive analysis of socio-demographic (i.e. sex and age), socioeconomic (i.e. level of education and monthly income of family), and other identified factors (i.e. type of membership and some patient-identified factors) was first done. For age, rates of underutilization were compared across the following age groups: 19-29 years old, 30 to 59 years old, and 60 and above years old. For monthly family income, the following strata were used: below $\mathrm{PhP} 3,500 ; \mathrm{PhP} 3,500$ to below 6,000; PhP 6,000 to below 9,500; PhP 9,500 to below 15,000; and PhP 15,000 and above. Patterns in education were assessed for the following strata: No grade completed, Elementary Graduate, High School Graduate, College Graduate, Graduate/Postgraduate Data that were collected were presented using contingency tables.

To determine the association of PhilHealth utilization to socio-demographic and socioeconomic factors, a chi-square test of association was employed. The encoded data were used to compute for chi-square and the p-values. Conclusions regarding the association of each factor to PhilHealth utilization were then made on the basis of the value of chi-square or the $\mathrm{p}$-value. The same test was done to compare results across member groups.

\section{Results and Discussion}

In $38.78 \%$ of the interviewed households, there was at least one case of PhilHealth underutilization while a larger majority (61.22\%) was able to utilize PhilHealth in all their hospitalizations. While underutilization was found to be less, a significant proportion of households still have not maximized insurance use.

Results of the test of association revealed that three factors significantly affected underutilization. Gender ( $p$ value=0.034), Type of membership ( $p$-value=0.027), and Income ( $p$-value=0.026) were found to be significantly associated with insurance underutilization (Table 1).

For Gender, underutilization was found to be a more prevalent occurrence among males (Figure 1). The prevalence ratio revealed that females were 1.32 times more likely to utilize than males. Results obtained in other studies made in the US, Kenya and Armenia, also showed that females are found to be the more frequent users of insurance and are more likely to utilize the expected benefits. According to these studies, females have better healthseeking behavior, and hence, an increased tendency to explore different means to lessen the burden of paying for inpatient services. $8,9,15$ 
Table 1. Values on Socio-demographic, Socioeconomic, and Other Related Measures by Utilization Status from PhilHealth Members in Manila, 2012

\begin{tabular}{|c|c|c|c|c|c|c|}
\hline \multirow{2}{*}{\multicolumn{2}{|c|}{ Variables }} & \multicolumn{2}{|c|}{ CLM } & \multirow{2}{*}{ Chi-square } & \multirow{2}{*}{ Prevalence ratio } & \multirow{2}{*}{ P-value } \\
\hline & & Utilization & Underutilization & & & \\
\hline \multirow{4}{*}{ AGE } & 19 to 29 & $27(71 \%)$ & $11(29 \%)$ & \multirow{4}{*}{2.213} & ---- & \multirow{4}{*}{0.529} \\
\hline & 30 to 39 & $34(58 \%)$ & $25(42 \%)$ & & 0.81 & \\
\hline & 40 to 49 & $18(60 \%)$ & $12(40 \%)$ & & 0.84 & \\
\hline & 50 and above & $11(55 \%)$ & $9(45 \%)$ & & 0.77 & \\
\hline \multirow{2}{*}{${ }^{*}$ SEX } & ${ }^{+}$Male & $44(54 \%)$ & $38(46 \%)$ & \multirow{2}{*}{4.472} & ---- & \multirow{2}{*}{0.034} \\
\hline & Female & $46(71 \%)$ & $19(29 \%)$ & & 1.32 & \\
\hline \multirow{5}{*}{ *INCOME } & 3,500 to $5,999 \mathrm{PhP}$ & $10(71 \%)$ & $4(29 \%)$ & \multirow{5}{*}{14.379} & 2.14 & \multirow{5}{*}{0.026} \\
\hline & 6,000 to $9,499 \mathrm{PhP}$ & $10(48 \%)$ & $11(52 \%)$ & & 1.43 & \\
\hline & 9,500 to $14,999 \mathrm{PhP}$ & $19(54 \%)$ & $16(46 \%)$ & & 1.63 & \\
\hline & 14,500 to $34,999 \mathrm{PhP}$ & $32(70 \%)$ & $14(30 \%)$ & & 2.09 & \\
\hline & above $35,000 \mathrm{PhP}$ & $14(88 \%)$ & $2(13 \%)$ & & 2.63 & \\
\hline \multirow{2}{*}{$\begin{array}{l}\text { EDUCATIONAL } \\
\text { STATUS }\end{array}$} & + Elementary graduate & $4(50 \%)$ & $4(50 \%)$ & \multirow[b]{2}{*}{1.861} & ---- & \multirow[b]{2}{*}{0.394} \\
\hline & High school graduate & $43(57 \%)$ & $32(43 \%)$ & & 1.15 & \\
\hline \multirow{5}{*}{ *Type of Membership } & + Sponsored & $11(37 \%)$ & $19(63 \%)$ & \multirow{5}{*}{10.996} & ---- & \multirow{5}{*}{0.027} \\
\hline & Private employed & $55(69 \%)$ & $25(31 \%)$ & & 1.88 & \\
\hline & Public employed & $10(67 \%)$ & $5(33 \%)$ & & 1.82 & \\
\hline & $\mathrm{IPP}$ & $12(60 \%)$ & $8(40 \%)$ & & 1.64 & \\
\hline & OFW & $2(100 \%)$ & $0(0 \%)$ & & 2.73 & \\
\hline
\end{tabular}

Another factor found to be significantly associated with insurance underutilization was the Type of Membership. In the Philippines, data have shown that underutilization is a more prevalent occurrence among sponsored members. ${ }^{2}$ Descriptive analysis of the study data has shown that underutilization is indeed higher among sponsored members (Figure 2). The p-value shows that there is a significant association between underutilization and the type of membership. Prevalence ratios illustrate this association more clearly. Paying member groups have a higher likelihood of utilization compared to the non-paying sponsored members (Table 1). The likelihood of insurance utilization among individually-paying and public-employed members is shown to be 1.64 and 1.82 times greater than those of the sponsored members. While for privateemployed and OFWs, the likelihood of utilization is 1.88 and 2.73 times, respectively, greater than that of the sponsored members. This trend may be explained by the Indigent program's political nature. As membership among sponsored members may change in an annual basis, households enrolled may not be aware of their coverage let alone the benefits to which they are entitled to. ${ }^{4}$ Another possible explanation may be the fact that paying members pay their premiums themselves hence they get educated more on the mechanics of the health insurance. ${ }^{16}$ Also, hoping to get the most out of their premiums, the paying member groups may tend to explore their benefits more.

While several studies ${ }^{8,11-13}$ suggest that poorer households tend to benefit from their insurance more, results of this study showed a higher rate of underutilization among the poor (Figure 3). Rates of underutilization were shown to be less among households of the higher income groups while it was seen to be greater in both the $\mathrm{PhP} 0$ to 3,499 and PhP 6,000 to 9,499 income groups. Notably, the lowest income group (i.e. PhP 0 to 3,499) obtained the highest rate of underutilization (64\%).

Aside from these three factors, several patient-identified factors were also found to be associated with insurance underutilization. A majority of the respondents who underutilized their benefits perceived "lack of knowledge on PhilHealth benefits" and "lack of knowledge on filing claims" as prime factors affecting utilization (Table 2).

Table 2. P-values of Patient-identified Factors of PhilHealth Members in Selected Barangays in Manila, 2012

\begin{tabular}{lccc}
\hline Reason for underutilization & Yes & No & P-value \\
\hline Lack of knowledge on benefits & $32(56 \%)$ & $25(44 \%)$ & $<0.001$ \\
$\begin{array}{l}\text { Lack of knowledge on filing claims } \\
\text { Lack of cooperation from doctors in }\end{array}$ & $42(74 \%)$ & $15(26 \%)$ & $<0.001$ \\
$\begin{array}{l}\text { getting required documents } \\
\begin{array}{l}\text { Cumbersome or unmanageable } \\
\text { process }\end{array}\end{array}$ & $26(46 \%)$ & $31(54 \%)$ & $<0.001$ \\
$\begin{array}{l}\text { High transaction costs compared to } \\
\text { benefits }\end{array}$ & $21(37 \%)$ & $36(63 \%)$ & $<0.001$ \\
\begin{tabular}{l} 
Ineligible claim \\
\hline
\end{tabular} & $23(40 \%)$ & $34(60 \%)$ & $<0.001$ \\
\hline
\end{tabular}

Among those who underutilized, 56\% perceived "lack of knowledge on PhilHealth benefits" as a contributing factor in underutilization. Also, 74\% of the respondents perceived the "lack of knowledge on filing claims" as a factor which contributed to the non-availment of PhilHealth benefits. 
Forty-six percent $(46 \%)$ of respondents who underutilized PhilHealth in-patient benefits also perceived "lack of cooperation from doctors, in getting the required documents", and "cumbersome or unmanageable claims process" as causes of underutilization. Proportions of respondents with underutilized PhilHealth memberships for "lack of knowledge on PhilHealth Benefits", "high transaction costs compared to benefits", and "ineligible claim" are 56\%, 37\%, and $40 \%$, respectively.

Four percent $(4 \%)$ of the respondents indicated reasons for underutilization are: "Processing takes a long time," "Waiting for social worker" and "Membership card already lost its effectivity when it was given".

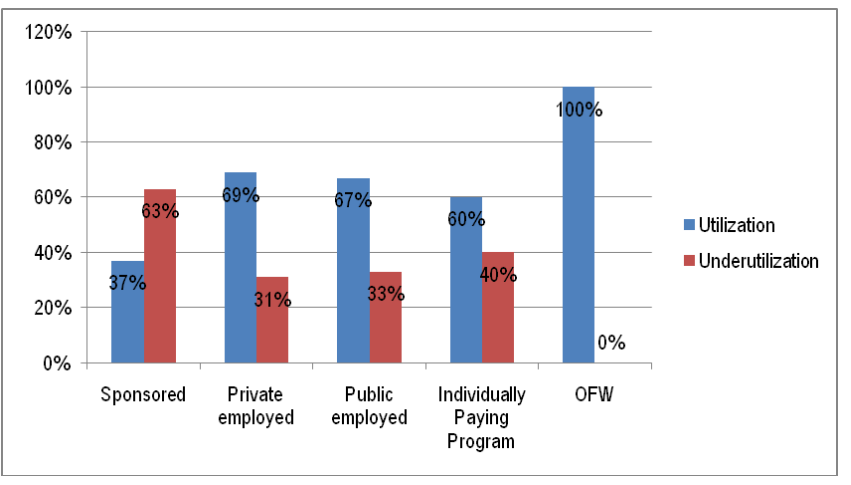

Figure 1. Utilization Status by Gender among PhilHealth Members in Selected Barangays in Manila, 2012

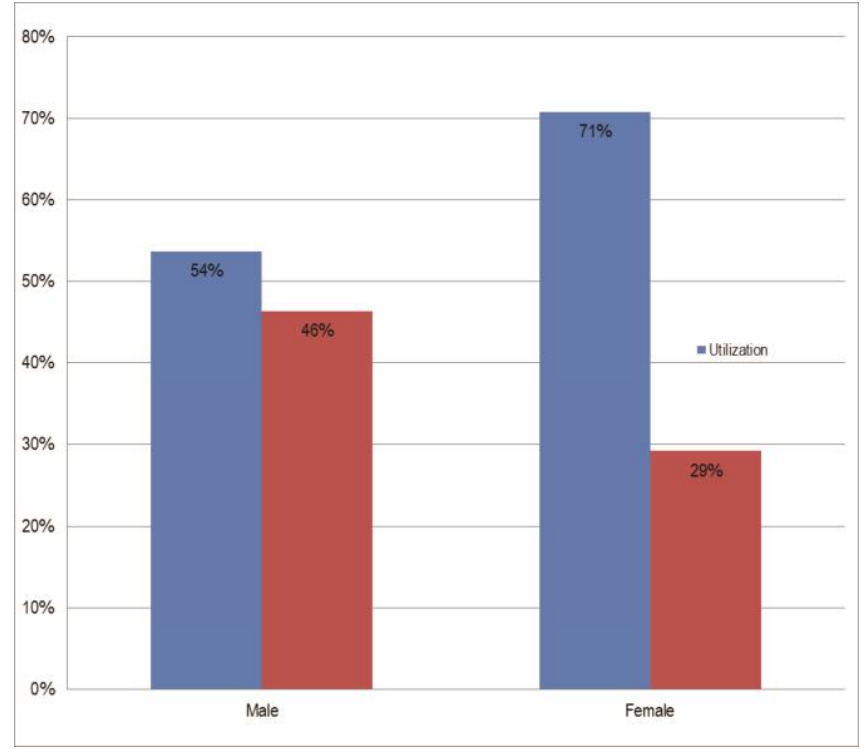

Figure 2. Utilization Status per Membership Type of PhilHealth Members in Selected Barangays in Manila, 2012

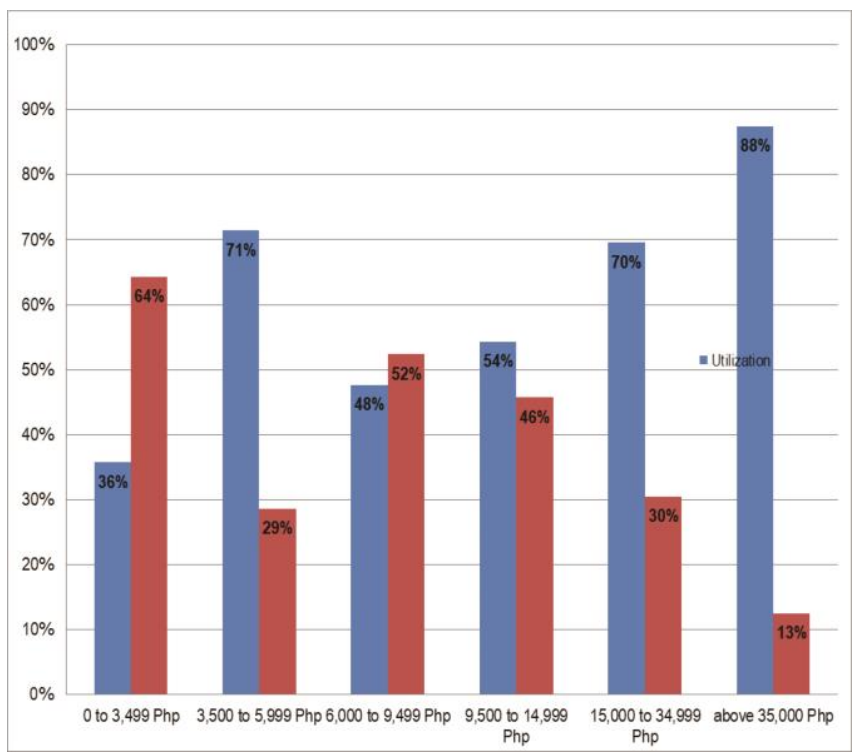

Figure 3. Utilization Status among Income Brackets of PhilHealth Members in Selected Barangays in Manila, 2012

\section{Conclusion}

Insurance underutilization is a problem less understood by many and is yet, crucial in attaining universal health care and ensuring equitable access to health care. This study sought to determine the association of certain "predictors" with the underutilization of PhilHealth inpatient benefits in selected barangays in Zone 77, Malate.

The projected underutilization rate of $38.78 \%$ - a significant proportion - demonstrates the need to address this problem. Results of this study may shed some light on this important question on underutilization. A significant finding points to the lack of knowledge of benefits and on filing claims as factors affecting insurance utilization.

This study validates the study done by Quimbo and colleagues in $2008^{4}$ and further shows that there is a statistically significant association between gender, income status, and type of membership among household PhilHealth respondents.

While PhilHealth's primary goal is to provide the poor, access to quality health care, it was found that families of the lowest wealth quintile and sponsored members are the very ones who are unable to make the most out of benefits received from PhilHealth. Ideally, these families should be able to maximize benefits through insurance utilization as they are particularly prone to ill-health. ${ }^{15}$

All of these have very important implications in policymaking and in improving service delivery, especially among the poor. They highlight the need to review and further strengthen existing mechanisms aimed at reaching out to PhilHealth's intended beneficiaries. Information campaigns should be heightened and hospital-based information dissemination systems should be strengthened to increase awareness of the services offered by PhilHealth. Additional 
policies must be created to provide incentives to increase utilization of inpatient benefits, to reduce the out-of-pocket payments, and, ultimately, to decrease health expenditures among members and improve the health status of the people.

\section{References}

1. Lim N. 'Conservative' and 'sluggish' PhilHealth misses healthcare target. GMA News Online [Online]. 2011 Apr 20 [cited 2012 Nov]. Available from http://www.gmanetwork.com/news/story/218278/ news/nation/conservative-and-sluggish-PhilHealth-misses-healthcaretarget.

2. Romualdez Jr. AG, dela Rosa JFE, Flavier JDA, et al. The Philippines Health System Review. Health Systems in Transition. 2011; 1(2). pp. 3940, p. 47

3. National Government posts highest growths on health expenditures... but households continue to bear most of the spending on health. National Statistical Coordination Board (NSCB) [Online]. 2013 [cited 2013 May]. Available from http://www.nscb.gov.ph/pressreleases/2013/ PR-20130606-SS1-01_PNHA.asp\#sthash.oX5WhIdD.dpuf

4. Quimbo S, Florentino J, Peabody JW, Shimkhada R, Panelo C, Solon O, Underutilization of social insurance among the poor: evidence from the Philippines. PLoS One. 2010; 3(10): e3379.

5. Erlyana E. Expanding health insurance to increase utilization: Does distance still matter? [PhD dissertation]. ProQuest; 2008. Available from University of Southern California Digital Library.

6. Clay OJ, Roth DL, Safford MM, Sawyer PL, Allman RM. Predictors of overnight hospital admission in older African American and Caucasian Medicare beneficiaries. J Gerontol A Biol Sci Med Sci. 2011 Aug; 66(8):910-6
7. Polonsky J, Balabanova D, McPake B, et al. Equity in community health insurance schemes: evidence and lessons from Armenia. Health Policy Plan. 2009; 24(3):209-216.

8. Mwaura JW, Pongpanich S. Access to health care: the role of a community based health insurance in Kenya. Pan Afr Med J. 2012; 12:35.

9. Grossman M. On the Concept of Health Capital and the Demand for Health. J Polit Econ. 1972; 80(2):223-55.

10. Limwattananon S, Tangcharoensathien $\mathrm{V}$, Tisayaticom $\mathrm{K}$, Boonyapaisarncharoen T, Prakongsai P. Why has the Universal Coverage Scheme in Thailand achieved a pro-poor public subsidy for health care? BMC Public Health. 2012; 12(Suppl 1):S6.

11. Medicare Chartbook. Fourth Edition. The Henry J. Kaiser Family Foundation. 2010. Figure 2.3. Inpatient Hospital Utilization by Medicare Beneficiaries by Demographic Characteristics, 2006; p. 23.

12. Veugelers PJ, Yip AM. Socioeconomic disparities in health care use Does universal coverage reduce inequalities in health? J Epidemiol Community Health. 2003; 57(6):424-8.

13. Dilip TR. Utilization of inpatient care from private hospitals: trends emerging from Kerala, India. Health Policy Plan. 2010; 25(5):437-46.

14. Mtei G, Makawia S, Ally M, Kuwawenaruwa A, Meheus F, Borghi J. Who pays and who benefits from health care? An assessment of equity in health care financing and benefit distribution in Tanzania. Health Policy Plan. 2012; 27(Suppl 1):i23-34.

15. National Statistics Office. National Demographic and Health Survey [Online]. 2008 [cited 2013 March]. Available from http://www.measuredhs.com/pubs/pdf/FR224/FR224.pdf

16. Asgary A, Willis K, Taghvaei AA, Rafeian M. Estimating rural households' willingness to pay for health insurance. Eur J Health Econ. 2004; 5(3):209-15.

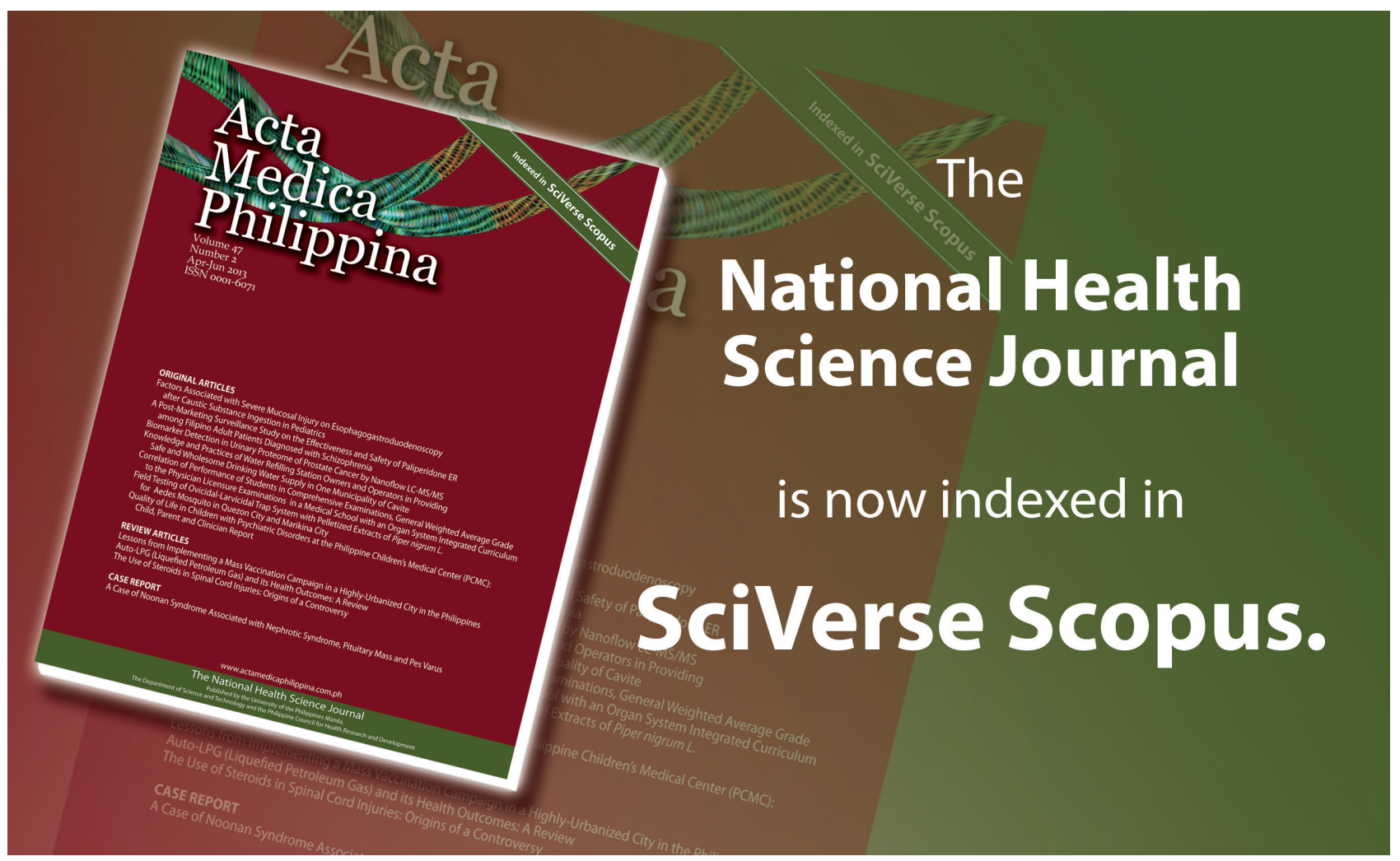

